\title{
Effect of Aging Time on Shape Memory Properties of Sputtered Ni-rich $\mathrm{Ni}_{2} \mathrm{MnGa}$ Alloy Films
}

\author{
Motohiko Suzuki ${ }^{1, *}$, Makoto Ohtsuka, Minoru Matsumoto, Yasukazu Murakami, \\ Daisuke Shindo and Kimio Itagaki \\ ${ }^{1}$ Institute of Multidisciplinary Research for Advanced Materials, Tohoku University, Sendai 980-8577, Japan
}

$\mathrm{Ni}_{2} \mathrm{MnGa}$ alloy is an intelligent material with ferromagnetic and shape memory properties. The application of the alloy films to microactuators has been proposed. The Ni-rich $\mathrm{Ni}_{2} \mathrm{MnGa}$ alloy films with a thickness of nearly $5 \mu$ m were deposited on $\mathrm{Al}_{2} \mathrm{O}_{3}$ substrates by a radio-frequency magnetron sputtering apparatus using a $\mathrm{Ni}_{52} \mathrm{Mn}_{24} \mathrm{Ga}_{24}$ target. They were heat-treated at $1073 \mathrm{~K}$ for $36 \mathrm{ks}$ for homogenization and ordering. The martensitic transformation temperatures of the heat-treated films were higher than room temperature. To investigate the effect of aging time on shape memory properties, the heat-treated films were aged at $673 \mathrm{~K}$ for various times between 0.9 and $57.6 \mathrm{ks}$ in a constrained condition. The constraint-aged films showed the two-way shape memory effect by thermal cycling. Fine precipitates with a crystal structure of $\mathrm{L}_{2}$ were observed in the constraint-films aged for a long period. As for their two-way shape memory properties, a range of transformation temperature narrowed and the amount of macroscopic shape change increased with increasing aging time.

(Received November 21, 2001; Accepted February 15, 2002)

Keywords: nickel-manganese-gallium, shape memory alloy, sputter-deposition, martensitic transformation, constraint-aging, two-way shape memory effect, precipitate

\section{Introduction}

The ternary intermetallic compound $\mathrm{Ni}_{2} \mathrm{MnGa}$ has ferromagnetic and martensitic transformation properties as first reported by Webster et al. ${ }^{1)}$ It has the Heusler-type cubic crystal structure of $\mathrm{L} 22_{1}$ at high temperature and some martensitic crystal structures at low temperature. ${ }^{1-3)}$ The martensitic transformations occur in the ferromagnetic temperature region and can be controlled not only by temperature and stress but also by magnetic field. ${ }^{4)}$ However, the Ni-Mn-Ga bulk alloy is too brittle to be formed in a required shape. Furthermore, it has a disadvantage of very slow response to the shape memory effect.

To solve these problems, the use of the Ni-Mn-Ga alloy films prepared by the sputtering method has been proposed by the authors. ${ }^{5-8)}$ It may be applied for an actuator of micromachines. The films with heat treatment at $1073 \mathrm{~K}$ showed high crystallinity and martensitic transformations.5) When their use around room temperature is considered, martensitic transformations and the Curie temperature should be higher than room temperature. It was found that the heattreated $\mathrm{Ni}$-rich $\mathrm{Ni}_{2} \mathrm{MnGa}$ alloy films met this requirement and showed the one-way shape memory effect. ${ }^{6}$ Furthermore, the two-way shape memory effect (TWME) was found to be induced by the plastic deformation ${ }^{7)}$ and the constraint-aging method. ${ }^{8)}$ It is commonly accepted that the occurrence of the TWME has been ascribed to the relaxation of inhomogeneous stress fields in the parent phase by the formation of the preferentially oriented variants. The inhomogeneous stress fields will be generated for precipitates, a part of stress-induced martensitic phases and so on. In the present study, the occurrence of precipitates and the effect of aging time on the shape memory properties were investigated with respect to the heat-treated $\mathrm{Ni}$-rich $\mathrm{Ni}_{2} \mathrm{MnGa}$ alloy films prepared by the constraint-aging method.

\footnotetext{
*Graduate Student, Tohoku University.
}

\section{Experimental Procedure}

\subsection{Preparation of films}

Ni-rich $\mathrm{Ni}_{2} \mathrm{MnGa}$ alloy films for studies on the TWME were deposited on $\mathrm{Al}_{2} \mathrm{O}_{3}$ substrates (thickness, $0.15 \mathrm{~mm}$ ) by a radio-frequency (RF) magnetron sputtering apparatus using a $\mathrm{Ni}_{52} \mathrm{Mn}_{24} \mathrm{Ga}_{24}$ target. The sputtering conditions were as follows: base pressure, $<2.5 \times 10^{-4} \mathrm{~Pa}$; argon working-gas pressure, $6 \times 10^{-1} \mathrm{~Pa}$; substrate temperature, $323 \mathrm{~K}$; sputtering power, $400 \mathrm{~W}$. The thickness of the deposited films was attained at nearly $5 \mu \mathrm{m}$ by controlling the sputtering time. These deposited films were heat-treated at $1073 \mathrm{~K}$ for $36 \mathrm{ks}$ for homogenization and ordering, then, peeled from the $\mathrm{Al}_{2} \mathrm{O}_{3}$ substrates. Hereafter, these heat-treated films were called as $400 \mathrm{~W}-1073 \mathrm{~K}$-films.

Some of the $400 \mathrm{~W}-1073 \mathrm{~K}$-films with a flat shape were cut into $5 \mathrm{~mm} \times 12 \mathrm{~mm}$, deformed to a cylindrical shape, and then, fixed inside a silica tube whose inner diameter was $4 \mathrm{~mm}$. Some of these constrained $400 \mathrm{~W}-1073 \mathrm{~K}$-films were aged at $673 \mathrm{~K}$ for various times $\left(t_{\text {age }}\right)$ between 0.9 and $57.6 \mathrm{ks}$ in a flow of argon gas, then, rapidly cooled in air. One of the constrained $400 \mathrm{~W}-1073 \mathrm{~K}$-films was aged at $673 \mathrm{~K}$ for $432 \mathrm{ks}$ in a vacuum furnace, then, slowly cooled in it.

On the other hand, one of the $400 \mathrm{~W}-1073 \mathrm{~K}$-films was fastened between flat Mo plates, aged at $673 \mathrm{~K}$ for $3.6 \mathrm{ks}$ in a flow of argon gas, and then, rapidly cooled in air.

The other Ni-rich $\mathrm{Ni}_{2} \mathrm{MnGa}$ alloy films with different properties (chemical composition, martensitic transformation temperatures, and so on) from the $400 \mathrm{~W}-1073 \mathrm{~K}$-films were deposited at $50 \mathrm{~W}$ on poly-vinyl alcohol (PVA) substrates (thickness, $18 \mu \mathrm{m}$ ), which were soluble in hot water. These deposited films with a thickness of nearly $5 \mu \mathrm{m}$ were separated from the PVA substrates, then, heat-treated at $873 \mathrm{~K}$ for $36 \mathrm{ks}$ in a vacuum furnace. Hereafter, these heat-treated films were called as $50 \mathrm{~W}-873 \mathrm{~K}$-films. The $50 \mathrm{~W}-873 \mathrm{~K}-$ films were prepared to study the crystal structure and mi- 
crostructure.

\subsection{Characterization of prepared films}

$\mathrm{X}$-ray diffraction (XRD) studies for the heat-treated and aged $400 \mathrm{~W}-1073 \mathrm{~K}$-films were made using $\mathrm{Cu}-\mathrm{K} \alpha$ radiation on an X-ray diffractmeter (Rigaku, RAD-C) equipped with a heating stage in a temperature range from 303 to $373 \mathrm{~K}$. The measurements were made while these films were held at

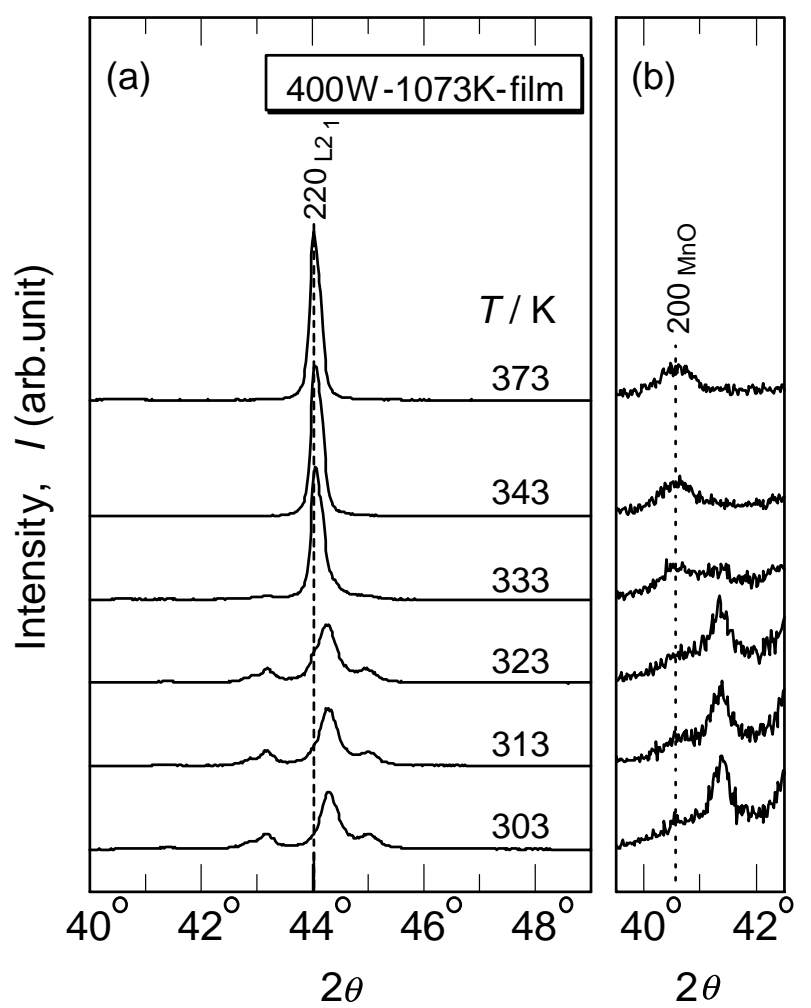

Fig. 1 XRD profiles of the $400 \mathrm{~W}-1073 \mathrm{~K}$-film in a temperature range from 303 to $373 \mathrm{~K}$. (a) shows the reversible martensitic transformation in heating prosess and (b) shows the existence of $\mathrm{MnO}$ phase. given temperatures in heating process. On the other hand, an XRD study for the $50 \mathrm{~W}-873 \mathrm{~K}$-film was made with a conventional X-ray diffractmeter (Rigaku, RINT2000) at room temperature. Transmission electron microscopy (TEM) studies and composition analyses were carried out using a transmission electron microscope (JEOL, JEM-3010) equipped with an energy dispersive X-ray spectrometer (EDS). Thin foils for the TEM examinations were prepared by twin jet electropolishing in an electrolyte consisting of $20 \mathrm{vol} \% \mathrm{HNO}_{3}-$ 80 vol\% $\mathrm{CH}_{3} \mathrm{OH}$.

The shape memory behavior of the constraint-aged $400 \mathrm{~W}-$ $1073 \mathrm{~K}$-films was observed using a digital video camera (Sony, DCR-PC100) in a temperature range from 300 to $330 \mathrm{~K}$. Heating of these films was performed with a lump at $<0.04 \mathrm{~K} \cdot \mathrm{s}^{-1}$, and cooling at $<0.03 \mathrm{~K} \cdot \mathrm{s}^{-1}$.

\section{Results and Discussion}

\subsection{Characteristics of heat-treated films}

Chemical compositions, martensitic transformation temperatures and Curie temperatures of the heat-treated films were controlled by the sputtering power and heat-treatment conditions. ${ }^{5)}$ Their martensitic transformation temperatures increased with increasing nickel content, that is valence electron concentration $(e / a)$. The valence electron configuration was assumed to be $3 d^{8} 4 s^{2}$ for $\mathrm{Ni}, 3 \mathrm{~d}^{5} 4 \mathrm{~s}^{2}$ for $\mathrm{Mn}$ and $4 \mathrm{~s}^{2} 4 \mathrm{p}^{1}$ for $\mathrm{Ga}$. These configurations are commonly used in electronic band calculations for the Heusler alloys.

The compositions of the $50 \mathrm{~W}-873 \mathrm{~K}-$ film and $400 \mathrm{~W}-$ $1073 \mathrm{~K}$-film were $\mathrm{Ni}-23.4 \mathrm{~mol} \% \mathrm{Mn}-23.0 \mathrm{~mol} \% \mathrm{Ga}(e / a=$ 7.69) and $\mathrm{Ni}-24.6 \mathrm{~mol} \% \mathrm{Mn}-21.7 \mathrm{~mol} \% \mathrm{Ga}(e / a=7.74)$, respectively. ${ }^{6)}$ Although the martensitic transformation temperature of the $50 \mathrm{~W}-873 \mathrm{~K}$-film was lower, that of the $400 \mathrm{~W}-$ $1073 \mathrm{~K}$-film was higher than room temperature. The reasons why they are rather different in spite of the fact that nickel content (that is $e / a$ ) of each film is similar to each other will be that the nickel content in the matrix and the degree of order
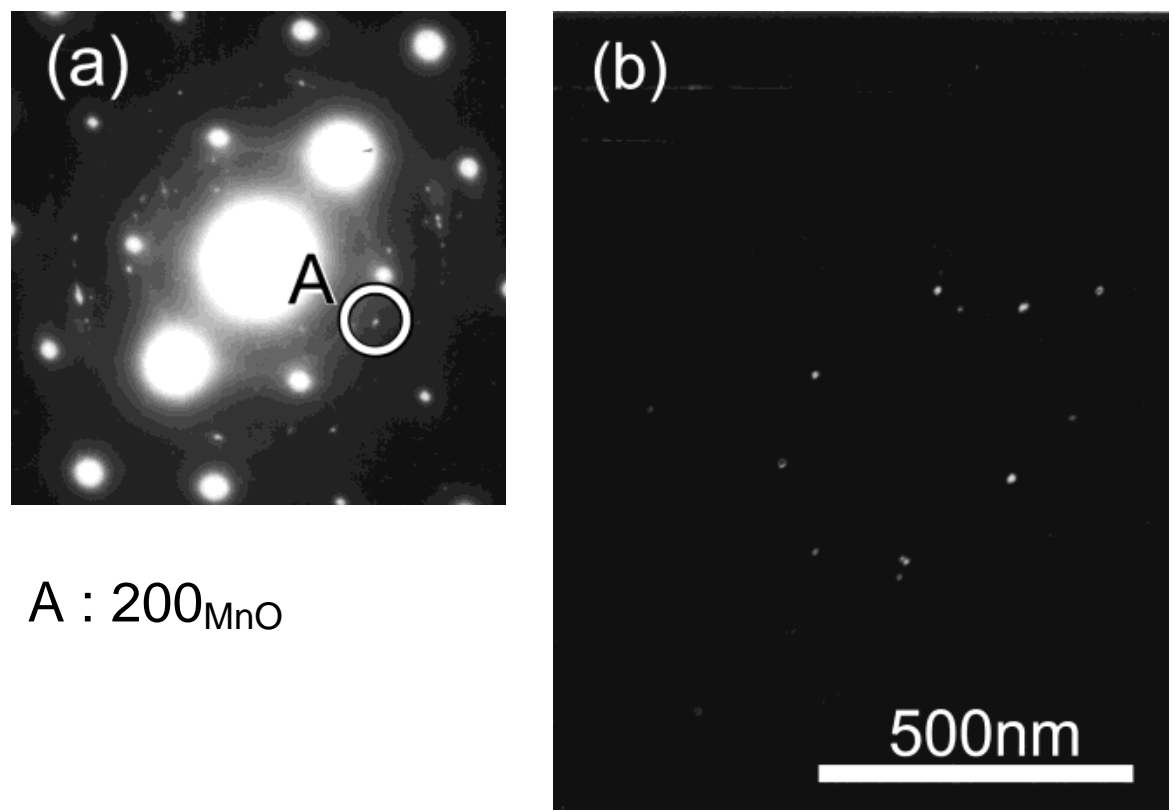

Fig. 2 (a) selected area diffraction and (b) TEM dark field image using reflection spot A for the $400 \mathrm{~W}-1073 \mathrm{~K}$-film at room temperature. 
in the film are different.

Figures 1(a) and (b) show the XRD profiles of the $400 \mathrm{~W}-$ $1073 \mathrm{~K}$-film in a temperature range from 303 to $373 \mathrm{~K}$. Figure 1(b) enlarged intensity of the diffraction patterns in Fig. 1(a) around $2 \theta$ of $41^{\circ}$. In Fig. 1(a), three diffraction peaks representing the martensitic phase clearly appear in a temperature range from 303 to $323 \mathrm{~K}$ and the (220) diffraction peak of the parent phase (L2 1 structure) from 333 to $373 \mathrm{~K}$. In Fig. 1 (b), the (200) peak of the $\mathrm{MnO}$ phase appears around $2 \theta$ of $40.6^{\circ}$ at all temperature range. Figures $2(a)$ and (b) show the serected area diffraction and the TEM dark field image using the (200) reflection spot of the $\mathrm{MnO}$ phase exhibited in $\mathrm{A}$ circle, respectively, for the $400 \mathrm{~W}-1073 \mathrm{~K}$-film at room temperature. In Fig. 2(b), it can be confirmed that the $\mathrm{MnO}$ particles with the sizes of about $10 \mathrm{~nm}$ homogeneously distributed in the matrix. These results indicate that the $\mathrm{MnO}$ particles always exist in the heat-treated films.

Figures 3(a), (b) and (c) show the XRD profile, the selected area diffraction and the TEM dark field image using the reflection spot exhibited in B circle, respectively, for the $50 \mathrm{~W}-$ $873 \mathrm{~K}$-film at room temperature. In Figs. 3(a) and (b), in addition to diffraction peaks and reflection spots representing the parent and $\mathrm{MnO}$ phase, two peaks and spots representing the phase with the crystal structure of $\mathrm{L}_{2}$ appear, respectively. In Fig. 3(c), it is confirmed that the precipitates with the sizes of about $50-100 \mathrm{~nm}$ occur in this film. Also, it was found by the EDS analysis that the composition of the precipitates was $\mathrm{Ni}-14.7 \mathrm{~mol} \% \mathrm{Mn}-13.3 \mathrm{~mol} \% \mathrm{Ga}$. Consequently, on the heat-treatment at comparatively low temperature, the precipitation of a compound with the approximate compositions of

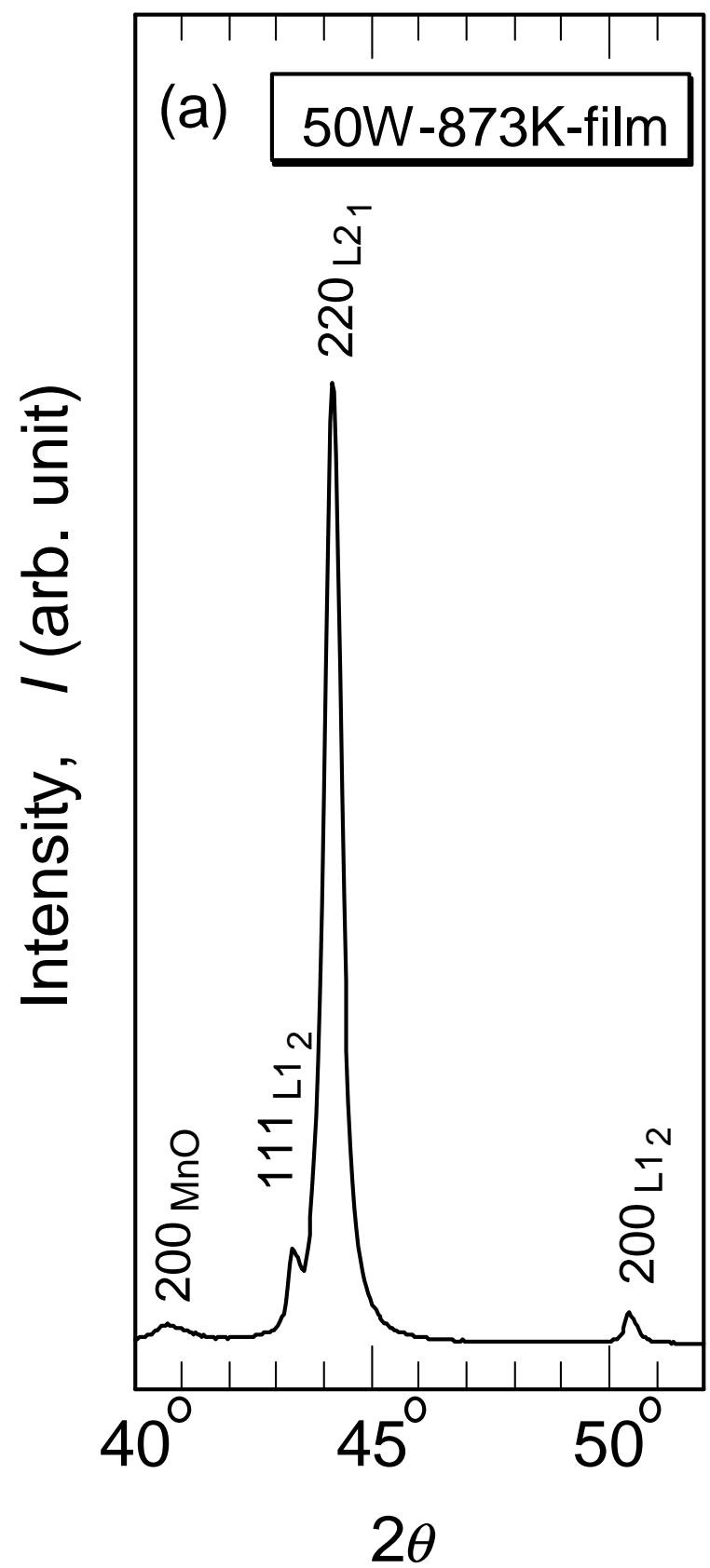

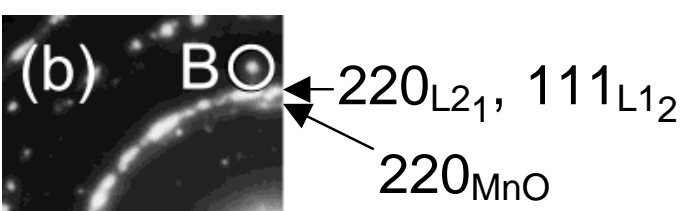
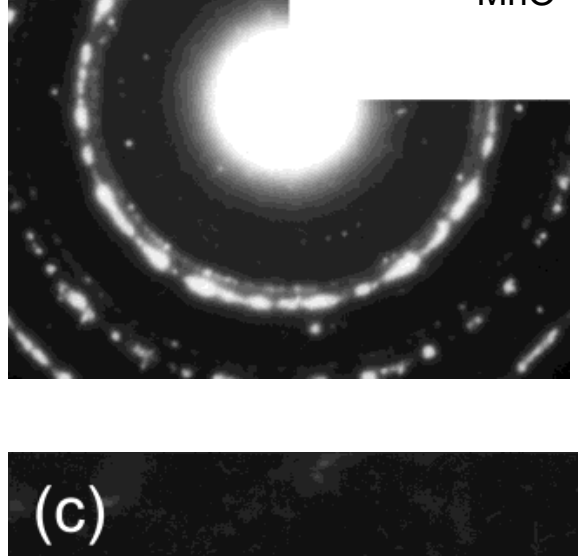

\section{$200 n m$}

Fig. 3 (a) XRD profile, (b) selected area diffraction and (c) TEM dark field image using reflection spot B for the 50 W-873 K-film at room temperature. 
$\mathrm{Ni}_{3}\left(\mathrm{Mn}_{0.6} \cdot \mathrm{Ga}_{0.4}\right)$ with the crystal structure of $\mathrm{L}_{2}$ occurs in the films. On the precipitation of $\mathrm{L1}_{2}$, the nickel content in the matrix decreases, as a result, it is assumed that the martensitic transformation temperatures of this film decrease.

\subsection{Characteristics of constraint-aged films}

Figures 4(a) and (b) show the TEM bright field image and the selected area diffraction of the $400 \mathrm{~W}-1073 \mathrm{~K}$-films constraint-aged at $673 \mathrm{~K}$ for $432 \mathrm{ks}$. The TEM observation was made at room temperature. It was observed in Fig. 4(a) that the fine particles with the sizes of about $10 \mathrm{~nm}$ homogeneously distributed into this film. Also, in addition to the strong reflection spots of the martensite phase, the (200) spot of the $\mathrm{MnO}$ phase and (111) spot of $\mathrm{L}_{2}$ were seen in $\mathrm{C}$ and D circles, respectively. Figures 4(c) and (d) show the TEM dark field images taken using the reflection spots in the $\mathrm{C}$ and $\mathrm{D}$ circles, respectively. Although the number of the precipitates with the crystal structure of $\mathrm{L1}_{2}$ is smaller than the
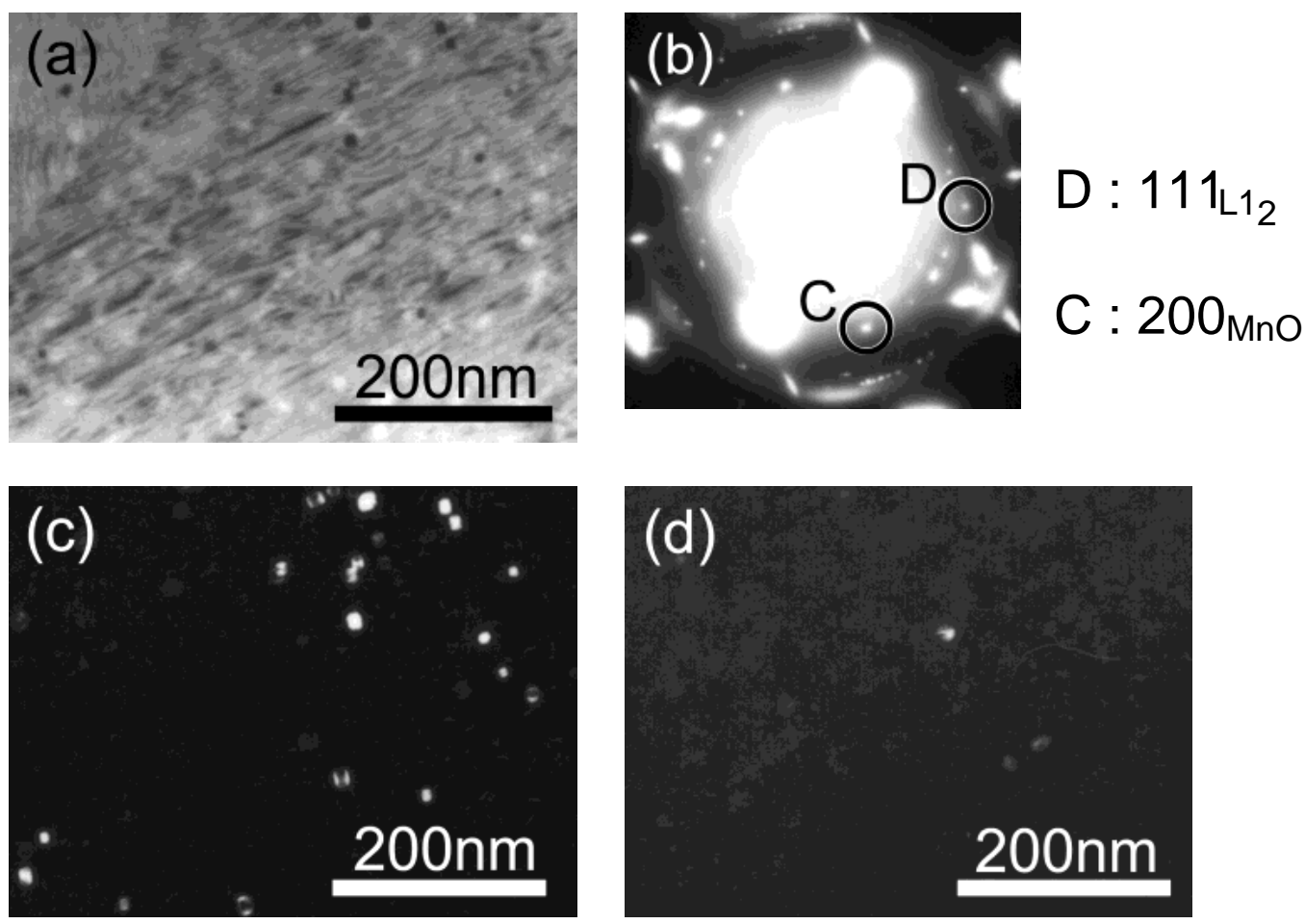

Fig. 4 (a) TEM bright field image, (b) selected area diffraction, (c) TEM dark field image using reflection spot $\mathrm{C}$ and (d) TEM dark field image using reflection spot $\mathrm{D}$ for the constraint-aged $400 \mathrm{~W}-1073 \mathrm{~K}$-film $\left(t_{\text {age }}=432.0 \mathrm{ks}\right)$ at room temperature.
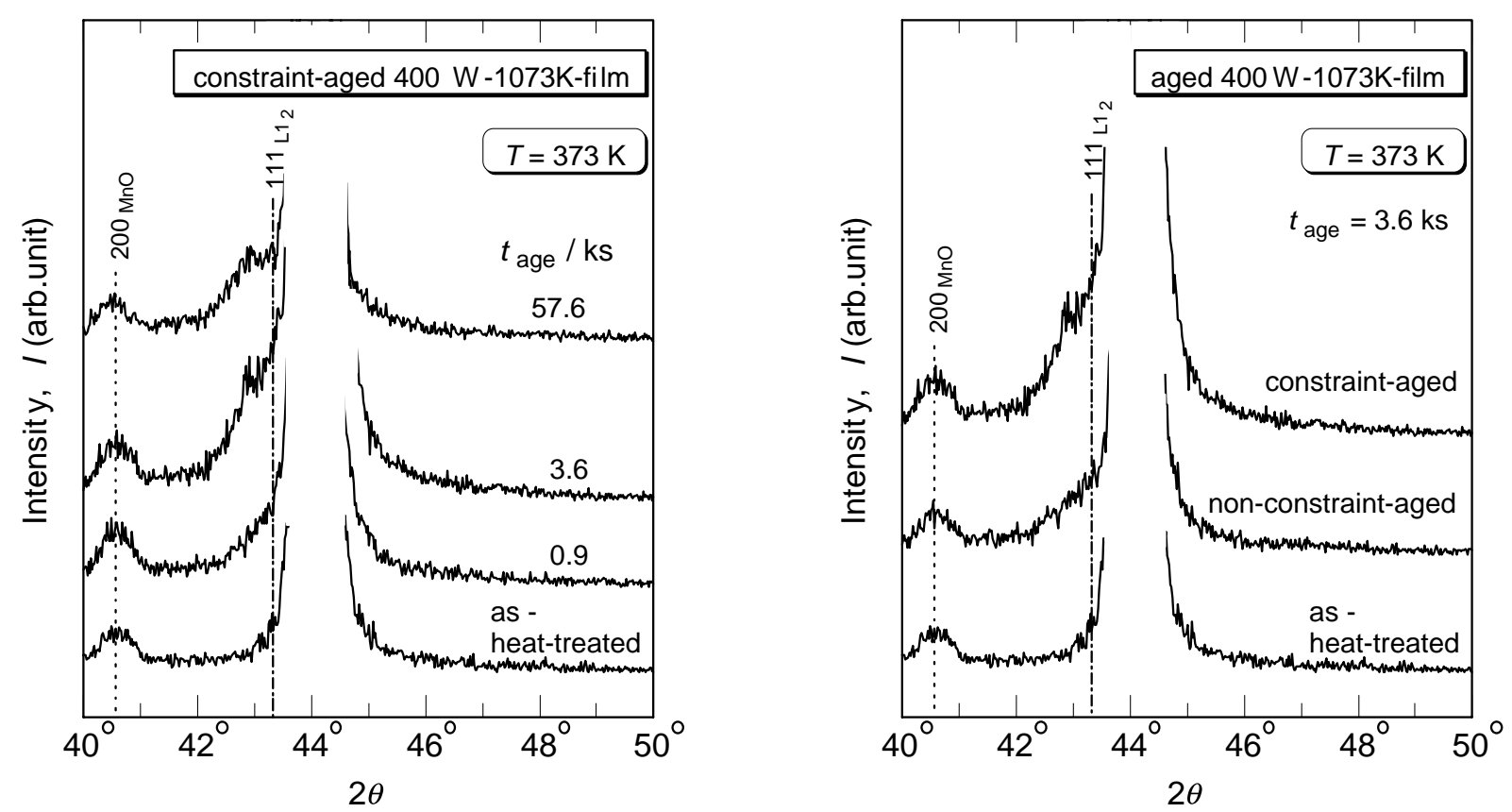

Fig. 5 Effect of aging time on XRD profiles for the constraint-aged Fig. 6 Effect of aging method on XRD profiles for the aged $400 \mathrm{~W}-1073 \mathrm{~K}-$ films $400 \mathrm{~W}-1073 \mathrm{~K}-$ films at $373 \mathrm{~K}$. 
$\mathrm{MnO}$ phase, the fine precipitates homogeneously distributed into this film as seen in Figs. 3(c) and (d). Consequently, on constraint-aging at $673 \mathrm{~K}$ for $432 \mathrm{ks}$, the precipitation of $\mathrm{L}_{2}$ takes place in the $400 \mathrm{~W}-1073 \mathrm{~K}$-film.

Figure 5 shows XRD profiles for the $400 \mathrm{~W}-1073 \mathrm{~K}-$ film constraint-aged at $673 \mathrm{~K}$ for 0.9 to $57.6 \mathrm{ks}$. The XRD measurements were made while the films were held at $373 \mathrm{~K}$. In addition to the diffraction peaks representing the parent phase and the $\mathrm{MnO}$ phase, a very weak diffraction peak representing the precipitation of $\mathrm{L}_{2}$ appears slightly around $2 \theta$ of $43.3^{\circ}$ in the profiles of the $400 \mathrm{~W}-1073 \mathrm{~K}$-films constraint-aged for 3.6 and $57.6 \mathrm{ks}$. Furthermore, a weak diffraction peak appears around $2 \theta$ of $43^{\circ}$ in the profiles of all the constraintaged $400 \mathrm{~W}-1073 \mathrm{~K}$-film samples. This diffraction peak becomes strong with increasing aging time.
Figure 6 shows XRD profiles for the $400 \mathrm{~W}-1073 \mathrm{~K}-$ films non-constraint-aged and constraint-aged at $673 \mathrm{~K}$ for $3.6 \mathrm{ks}$. The XRD measurements were made while the films were held at $373 \mathrm{~K}$. Although a weak diffraction peak appears around $2 \theta$ of $43^{\circ}$ in the profile of the constraint-aged $400 \mathrm{~W}-1073 \mathrm{~K}-$ film, it doesn't appear in the profile of the non-constraint-aged $400 \mathrm{~W}-1073 \mathrm{~K}-\mathrm{film}$. As a result of the XRD studies, it is considered that the phase corresponding to this peak may be a stress-induced martensitic one.

\subsection{Effect of aging time on shape memory properties}

The $400 \mathrm{~W}-1073 \mathrm{~K}$-films after constraint-aging at $673 \mathrm{~K}$ for $0.9-57.6 \mathrm{ks}$ were taken out of the silica tube and heated or cooled in a temperature range around the martensitic transformation temperatures. Figures 7(1) and (2) show the changes

\section{(1) $t_{\text {age }}=0.9 \mathrm{ks}$}

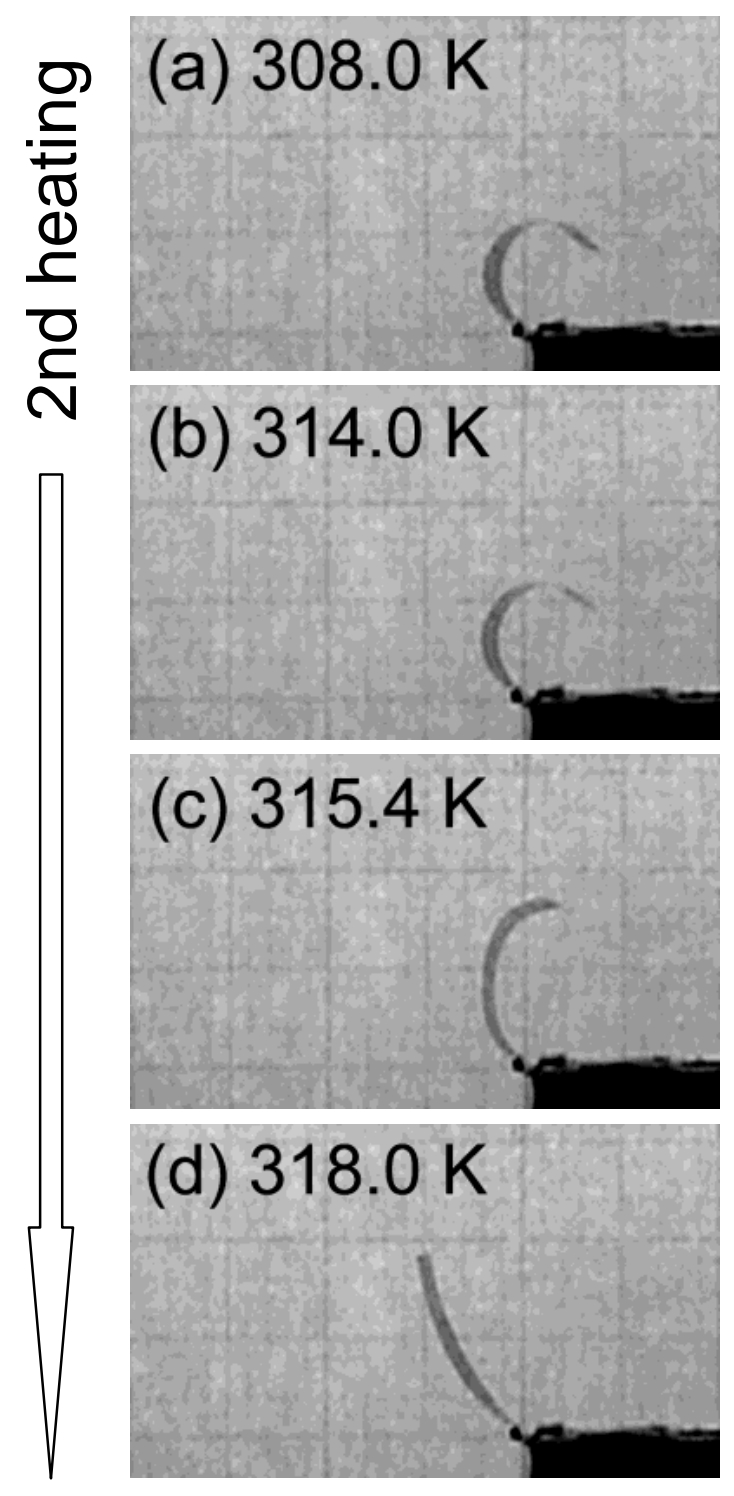

\section{(2) $t_{\text {age }}=57.6 \mathrm{ks}$}
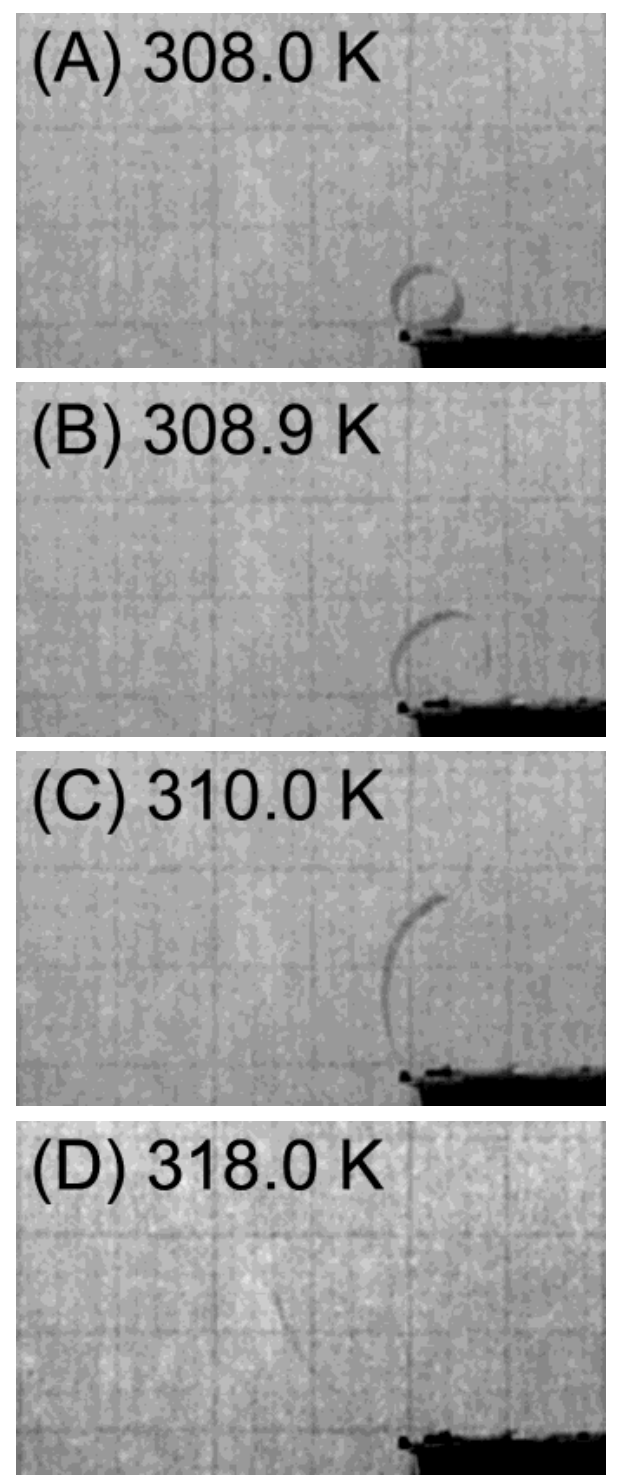

$10 \mathrm{~mm}$

Fig. 7 Effect of aging time on shape memory behavior for the constraint-aged $400 \mathrm{~W}-1073 \mathrm{~K}$-films in the 2nd heating stage. (1) $t_{\text {age }}=0.9 \mathrm{ks}$ and (2) $t_{\text {age }}=57.6 \mathrm{ks}$. 


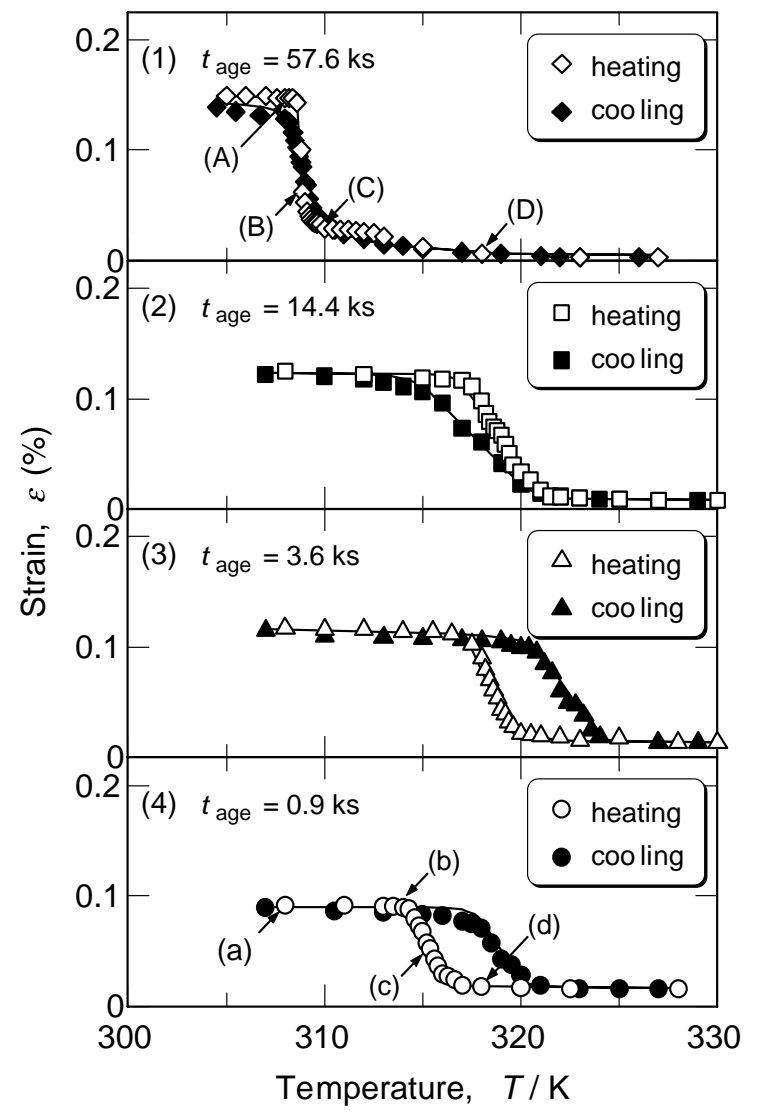

Fig. 8 Effect of aging time on temperature-strain curves for the constraint-aged $400 \mathrm{~W}-1073 \mathrm{~K}$-films in the 2 nd heating and cooling stages. (A)-(D) in (1) and (a)-(d) in (4) correspond to (A)-(D) in Fig. 7(2) and (a)-(d) in Fig. 7(1), respectively.

in the shape of $400 \mathrm{~W}-1073 \mathrm{~K}$-films constraint-aged for 0.9 and $57.6 \mathrm{ks}$, respectively, in the 2 nd heating. Figure 8 shows the temperature-strain curves obtained from the shape change in the 2nd thermal cycling. The strain at the outer surface was given by $\varepsilon=\left(d_{\mathrm{S}} / 2\right) / r_{T}$, where $d_{\mathrm{S}}$ is the thickness of films and $r_{T}$ is the radius of a curvature for the bent films at each temperature. It is clear that the constraint-aged $400 \mathrm{~W}-$ $1073 \mathrm{~K}$-films show the TWME. The width of thermal hysteresis, which decreases with increasing aging time, is about $2 \mathrm{~K}$ when the aging time is $57.6 \mathrm{ks}$. Also, the reversible strain increases with increasing aging time. Furthermore, the temperatures of the shape change increase with increasing aging time up to $14.4 \mathrm{ks}$, then, they decrease with increasing aging time. These results suggest that both of the stress-induced martensitic phase and the precipitates exist as the inhomo- geneous stress fields in the constraint-aged $400 \mathrm{~W}-1073 \mathrm{~K}$ films. When the aging time is short, the stress-induced martensitic phase is considered to be mainly responsible for the TWME of the constraint-aged $400 \mathrm{~W}-1073 \mathrm{~K}$-films. Also, the precipitates are considered to be responsible for it with increasing aging time. The $\mathrm{MnO}$ particles may have no effect on the TWME because they always exist in the $400 \mathrm{~W}-1073 \mathrm{~K}$ films. A further study is needed to clarify its mechanism.

\section{Summary}

Ni-rich $\mathrm{Ni}_{2} \mathrm{MnGa}$ films were deposited on an $\mathrm{Al}_{2} \mathrm{O}_{3}$ substrate with a RF magnetron sputtering apparatus using a $\mathrm{Ni}_{52} \mathrm{Mn}_{24} \mathrm{Ga}_{24}$ target. The occurrence of precipitates and the effect of aging time on shape memory properties were investigated at various constraint-aging method.

The obtained results are summarized as follows:

(1) The fine precipitates with crystal structure of $\mathrm{L}_{2}$ occured in the constraint-aged $400 \mathrm{~W}-1073 \mathrm{~K}$-films by aging for a long period.

(2) The thermal hystersis on the TWME of the constraintaged $400 \mathrm{~W}-1073 \mathrm{~K}$-films decreases with increasing aging time.

(3) The reversible strain on the TWME of constraint-aged $400 \mathrm{~W}-1073 \mathrm{~K}$-films increases with increasing aging time.

\section{Acknowledgements}

The authors are grateful to Prof. T. Suzuki, Faculty of Engineering, Tohoku Gakuin University, for the measurement of XRD. This study was supported by Industrial Technology Research Grant Program in '01 from New Energy and Industrial Technology Development Organization (NEDO) of Japan.

\section{REFERENCES}

1) P. J. Webster, K. R. A. Ziebeck, S. L. Town and M. S. Peak: Philos. Mag. B 49 (1984) 295-310.

2) J. Pons, V. A. Chernenko, R. Santamarta and E. Cesari: Acta Mater. 48 (2000) 3027-3038.

3) B. Wedel, M. Suzuki, Y. Murakami, C. Wedel, T. Suzuki, D. Shindo and K. Itagaki: J. Alloys Comp. 290 (1999) 137-143.

4) K. Ullakko: J. Mater. Eng. Perform. 5 (1996) 405-409.

5) K. Ohi, S. Isokawa, M. Ohtsuka, M. Matsumoto and K. Itagaki: Trans. Mater. Res. Soc. Japan 26 (2001) 291-294.

6) M. Ohtsuka and K. Itagaki: Int. J. Appl. Electromagn. Mech. 11 (2000) 49-59.

7) M. Ohtsuka, M. Matsumoto and K. Itagaki: Trans. Mater. Res. Soc. Japan 26 (2001) 201-204.

8) S. Isokawa, M. Suzuki, M. Ohtsuka, M. Matsumoto and K. Itagaki: Mater. Trans. 42 (2001) 1886-1889. 